\title{
RIA Analysis of Unprotected TRIGA Reactor
}

\author{
M.H. Altaf ${ }^{1}$, S.M. Tazul Islam ${ }^{2}$ and N.H. Badrun ${ }^{1^{*}}$ \\ ${ }^{I}$ Reactor Physics and Engineering Division (RPED), Institute of Nuclear Science and Technology (INST), \\ Atomic Energy Research Establishment (AERE), Ganakbari, Savar, Dhaka, Bangladesh \\ ${ }^{2}$ Department of Physics, Government BM College, Barisal, Bangladesh
}

\section{ARTICLE INFO}

Article history:

Received 27 November 2016

Received in revised form 06 April 2017

Accepted 10 April 2017

Keywords:

Unprotected TRIGA

RIA

Doppler feedback

Cladding temperature

\begin{abstract}
A B S T R A C T
An RIA (reactivity initiated accident) analysis has been carried out for the TRIGA Mark II research reactor considering both step and ramp reactivity ranges within $0.5 \% \mathrm{dk} / \mathrm{k}(<\$ 1)$ to $2.0 \% \mathrm{dk} / \mathrm{k}(>\$ 2)$. The insertion time was set at $10 \mathrm{~s}$. Based on the fact that a reactor becomes unprotected if scram does not work at the event of danger, to define unprotected conditions, the time to actuate scram (trip) was taken as close to total simulation time. In this long duration of scram inactivity, it is obtained from the present analysis that the reactor remained safe to up to $1.8 \% \mathrm{dk} / \mathrm{k}$ (\$2.57) for step reactivity and $1.99 \% \mathrm{dk} / \mathrm{k}(\$ 2.84)$ for ramp reactivity. In addition to negative temperature coefficient of reativity, probably the longer time of reactivity insertion keeps TRIGA safe even at larger magnitudes of reactivity during unprotected reactor transients. Coupled point kinetics, neutronics, and thermal hydraulics code EUREKA-2/R has been utilized for this work. It appears that EUREKA-2/RR predicts the sequence of unprotected transient scenario of TRIGA core with good approximation and the results will definitely be helpful for the reactor operators.
\end{abstract}

(C) 2017 Atom Indonesia. All rights reserved

\section{INTRODUCTION}

In Bangladesh, there is a 3-MW TRIGA Mark II research reactor within the complex of Atomic Energy Research Establishment (AERE), Savar, Dhaka. It has been engaged in production of radioisotopes for uses in agriculture, industry, and medicine, and for conducting research and training manpower in various fields of nuclear science. Since its commissioning in 1986, a number of computer codes have been used to do thermal hydraulic and transient analysis of the TRIGA reactor as a part of its safety analysis. There are still some cases left unseen especially in the area of reactivity-induced transient. The reactivity-initiated accident (RIA) is a design basis accident and has received much attention due to its severe impacts on nuclear safety. The danger of RIA is that it could compromise fuel integrity due to overheating as the fission rates in the reactor core increases, and it increases the core power to an unexpectedly high level. For the purpose of safety analysis, it is customary to

* Corresponding author.

E-mail address: nhbadrun@yahoo.com

DOI: https://doi.org/10.17146/aij.2017.568 systematically consider transients with and without scram event, called protected and unprotected transients, respectively. The previously performed RIA analyses of TRIGA were limited to the protected transient [1-3] that is followed by reactor shutdown (scram). The unprotected transient will occur if the reactor protection system is assumed to fail when it is required to bring the reactor into the safe condition. In this unprotected situation, the safety of the reactor is solely dependent on the feedback reactivity inherent in the reactor. To fully understand the safety of reactor operation, safety analysis should be expanded to cover unprotected transients so the reactor operators could better benefit from any core modification, upgrade, or core conversion. RIA analysis for unprotected TRIGA has not been reported before. From this point of view, this paper aims to report the behavior of reactor core power and fuel cladding temperature of an unprotected TRIGA reactor and finally investigate the limit of inserted reactivity imposed by cladding melting temperature. Coupled point kinetics, neutronics, and thermal hydraulics code EUREKA-2/R has been utilized for this purpose [4]. 


\section{Modelling reactor unprotected and parametric study}

For detail modeling of TRIGA core, a paper previously published by two of the authors [1] is referred here. However, the modeling described in [1] was based on protected RIA. It could be recalled that to define a protected transient, the time to actuate scram is set very short, for instance, about $0.01 \mathrm{~s}$ in comparison to the total time of $70 \mathrm{~s}$ of transient simulation. This implies that within $0.01 \mathrm{~s}$, shutdown (control) rod start to be inserted into the core soon after the reactor receives the scram signal. In the present work, the same model as discussed in [1] was used, but instead of protected transients, unprotected transients needed to be defined. The way to do this is to extend the scram actuation time in the input. This time of scram actuation is set close to the total simulation time of $70 \mathrm{~s}$. This means that the control rod drop is delayed by $70 \mathrm{~s}$ after the trip signal is activated, which in turn indicates that the reactor remains unprotected for $70 \mathrm{~s}$ before scram is activated. In this long duration of unprotected transient, the behavior of reactor parameters, especially fuel cladding temperature, against different ranges of inserted reactivity is the main interest of the present study.

Both step and ramp reactivity in the $0.5 \%$ $\mathrm{dk} / \mathrm{k}(<\$ 1)$ to $2.0 \% \mathrm{dk} / \mathrm{k}(>\$ 2)$ range with an insertion time of $10 \mathrm{~s}$ have been considered. The reactor was in full power with forced convection mode. To investigate this maximum temperature, the common approach in practice is to sort out the hottest fuel rod from the core. If it can be ensured that the temperature of the hottest fuel rod remains below the core design limit, the remaining fuel rods will then presumably fall within this limit. Hence, focus has been paid to reporting the maximum cladding temperature that the hottest fuel rod of TRIGA reaches. It is also worth mentioning that as the steady state results for fuel, cladding, and coolant temperatures as discussed in [1] are similar for both protected and unprotected conditions of TRIGA, as already verified by the experimental results, the same steady-state model has been used here to define the reactors' unprotected RIA, and then a transient analysis has been carried out.

\section{RESULTS AND DISCUSSION}

Figures 1 and 2 present reactor power and cladding temperature, respectively, for step insertion of reactivity. Figure 1 shows the power transient as a function of time for step reactivity insertions of $0.5 \% \mathrm{dk} / \mathrm{k}, 1.5 \% \mathrm{dk} / \mathrm{k}, 1.9 \% \mathrm{dk} / \mathrm{k}$, and $2.0 \% \mathrm{dk} / \mathrm{k}$. It appears that under the $0.5 \% \mathrm{dk} / \mathrm{k}$ reactivity insertion, the reactor power rose sharply until it attained a maximum power of $6.12 \mathrm{MW}$ at $1 \mathrm{~s}$. From this maximum, it started decreasing and stabilized at $4.15 \mathrm{MW}$ at around $2.5 \mathrm{~s}$. For the $1.5 \% \mathrm{dk} / \mathrm{k}$ reactivity insertion, the reactor power increased rather rapidly to $17.5 \mathrm{MW}$ at $0.6 \mathrm{~s}$, then experienced another gradual increase until $19.30 \mathrm{MW}$ at $1 \mathrm{~s}$, followed by a sharp decrease from this value to $10.49 \mathrm{MW}$ at $1.2 \mathrm{~s}$, the reactor power continued to decrease slowly and stabilized at around $6.60 \mathrm{MW}$ at $2.5 \mathrm{~s}$. For the $2.0 \% \mathrm{dk} / \mathrm{k}$ reactivity insertion, power increased rather rapidly at first, reaching a first peak at $0.5 \mathrm{~s}$, with a peak value of $21.88 \mathrm{MW}$; it then decreased slightly to $21.54 \mathrm{MW}$ at $0.65 \mathrm{~s}$ and increased again until reaching $24.86 \mathrm{MW}$ at $1 \mathrm{~s}$. Afterward, power dropped rapidly to a value of $11.90 \mathrm{MW}$ at $1.2 \mathrm{~s}$ and then continued to decrease slowly and stabilized at 6.68 MW. Curiously, it has been observed that a $1.9 \% \mathrm{dk} / \mathrm{k}$ reactivity insertion resulted in a similar trend as obtained for $2.0 \% \mathrm{dk} / \mathrm{k}$. It is noticed from Fig. 1 that there is a tendency of ups and downs in the trend of power which becomes steeper with the increase of reactivity inserted. The effects of negative feedback reactivity seem to play a role in such performance of power profiles. Then, the next parameter observed was the behavior of fuel cladding temperature with the increase of power.

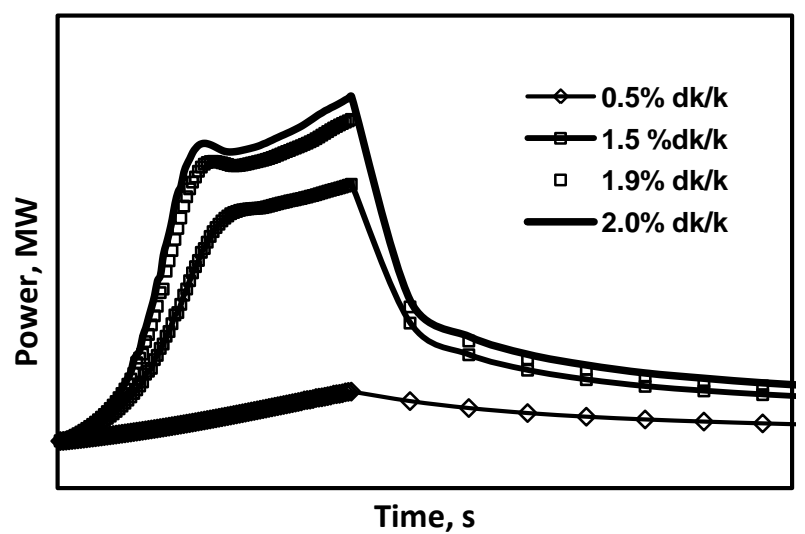

Fig. 1. Power transient behavior for different step reactivities.

Figure 2 presents the pattern of cladding temperature with the increased reactivity. It is noticed that at the beginning of temperature rise early in the transient, the cladding temperatures lay within the $143{ }^{\circ} \mathrm{C}$ to $175{ }^{\circ} \mathrm{C}$ range for the different amounts of reactivity; however, the trend of the temperature onward became severe subject to the increase of inserted reactivity. 


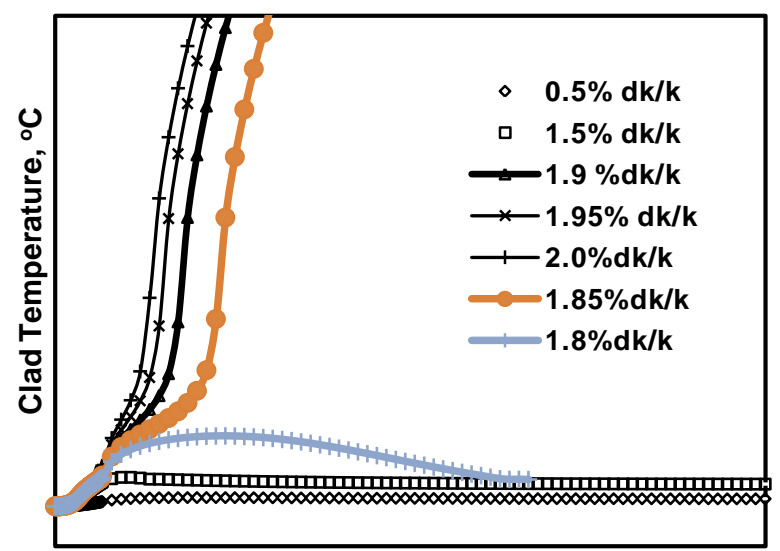

Time, $s$

Fig. 2. Fuel cladding temperature behavior for different step reactivities.

For $0.5 \% \mathrm{dk} / \mathrm{k}$ and $1.5 \% \mathrm{dk} / \mathrm{k}$ reactivity insertions, the cladding temperature stabilized at $145.69{ }^{\circ} \mathrm{C}$ and $162.08{ }^{\circ} \mathrm{C}$, respectively, which are below the $500{ }^{\circ} \mathrm{C}$ design limit of TRIGA reactor fuel cladding temperature. For $2.0 \% \mathrm{dk} / \mathrm{k}$, the temperature tended to exceed the design limit values. Similar behaviors were observed for $1.9 \%$ $\mathrm{dk} / \mathrm{k}$ and $1.95 \% \mathrm{dk} / \mathrm{k}$ step reactivity insertions. Later, two more values, $1.85 \% \mathrm{dk} / \mathrm{k}$ and $1.8 \%$ $\mathrm{dk} / \mathrm{k}$, were tried for step reactivity insertion. For $1.85 \% \mathrm{dk} / \mathrm{k}$, the temperature at second extent reached $266{ }^{\circ} \mathrm{C}$, but beyond this, steep increase of temperature exceeded the design value. For $1.8 \%$ $\mathrm{dk} / \mathrm{k}$, the temperature increased further until reaching $204{ }^{\circ} \mathrm{C}$ from which it dropped to $163{ }^{\circ} \mathrm{C}$ and then remained in this value over the entire transient period. Hence, for reactivities greater than $1.8 \% \mathrm{dk} / \mathrm{k}$, the reactor could not remain in the safe side as the cladding temperature exceeded the design limit within $3 \mathrm{~s}$ of transient for reactivity insertions of $1.85 \% \mathrm{dk} / \mathrm{k}, 1.9 \% \mathrm{dk} / \mathrm{k}, 1.95 \% \mathrm{dk} / \mathrm{k}$ and $2.0 \% \mathrm{dk} / \mathrm{k}$.

Figure 1 and Figure 2 illustrate that although the reactor operating power exceeded the trip level even at $0.5 \% \mathrm{dk} / \mathrm{k}$ reactivity insertion, cladding temperature did not instanteneously increase together with the increase of reactor power. Moreover, cladding temperature eventually returned to the steady state limit for reactivity insertions of up to $1.8 \% \mathrm{dk} / \mathrm{k}$, following some ups and downs in the trend. This behavior of slow incease in cladding temperature under rapid rise of reactor power can be characterized by a unique feature of TRIGA reactor which arises from the large prompt negative temperature coefficient of reactivity that is contributed by $\mathrm{U}-\mathrm{ZrH}$ fuel moderator material. Also, Doppler broadening of U-238 resonance played a vital role, as seen from Fig. 3 to Fig. 6 . For TRIGA LEU fuel, the contribution of Doppler feedback reactivity to the system per degree of temperature rise is relatively more significant than that of void/density coefficient and coolant temperature coeffiecient of reactivity [5]. Due to this factor, there was a rapid increase in cladding temperature until a certain point and, after a balance occurred between positive and negative reactivities, temperature reached steady-state levels for up to $1.8 \% \mathrm{dk} / \mathrm{k}$ reactivity. From $1.85 \% \mathrm{dk} / \mathrm{k}$ and beyond, the cladding temperature experienced a sharp increase and exceeded its design limit within a very short time. For such a fast transient, the heat transfer rate from cladding to coolant was too low to increase the coolant temperature beyond its saturation temperature and hence no nucleate boiling was predicted during the unprotected condition of reactor within the ranges of reactivity mentioned in this paper. Figure 3 shows the effect of Doppler reactivity with the increase of inserted reactivity.

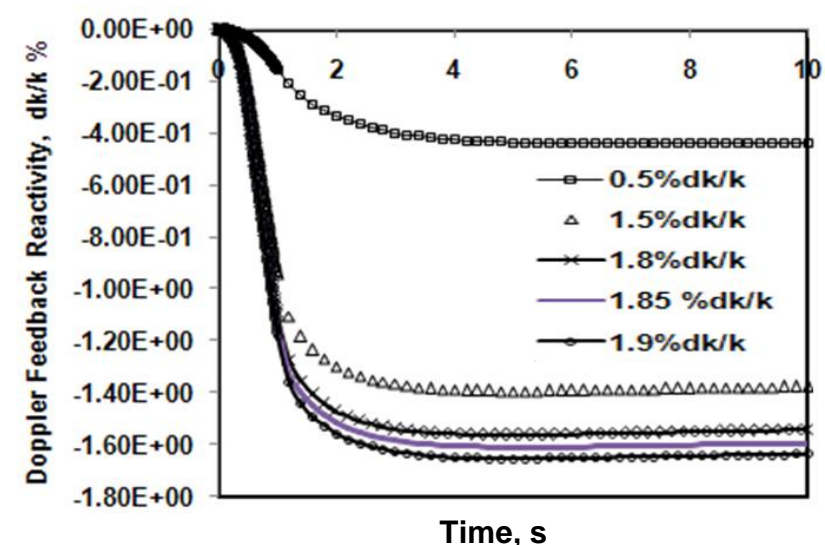

Fig. 3. Doppler feedback reactivity variation for different step reactivities.

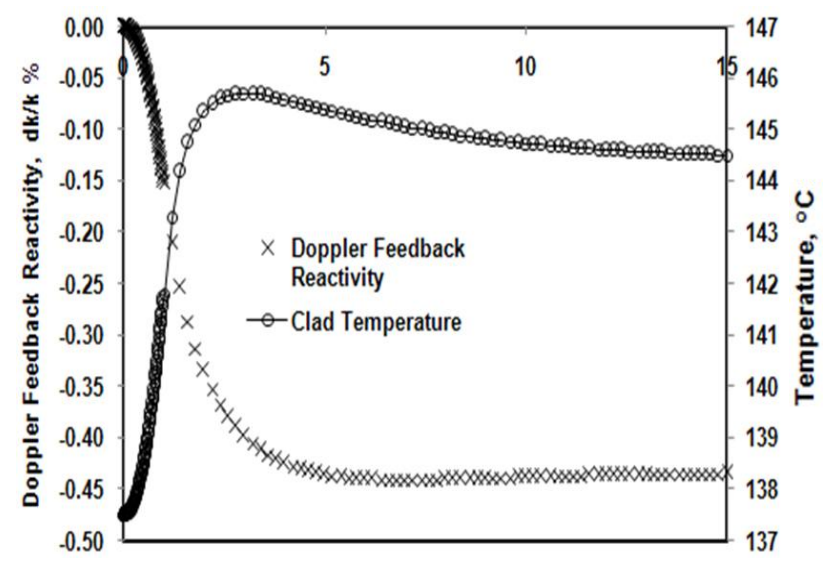

Fig. 4. Variation of cladding temperature with Doppler feedback reactivity for $0.5 \% \mathrm{dk} / \mathrm{k}$ step reactivity.

Figures 4 and 5 show the contributions of Doppler feedback reactivity to bringing the cladding temperature to the steady state range for $0.5 \% \mathrm{dk} / \mathrm{k}$ and $1.8 \% \mathrm{dk} / \mathrm{k}$ reactivity, and Fig. 6 illustrates that 
the failure of negative feedback reactivity to balance positive reactivity and cladding temperature at some stage started a sharp increase for $1.85 \% \mathrm{dk} / \mathrm{k}$ reactivity. Although feedback reactivity slightly increased from $1.8 \%$ to $1.85 \%$ as seen in Fig. 3, this effect is negligible in this domain, thus providing no control capable of bringing the cladding temperature down.

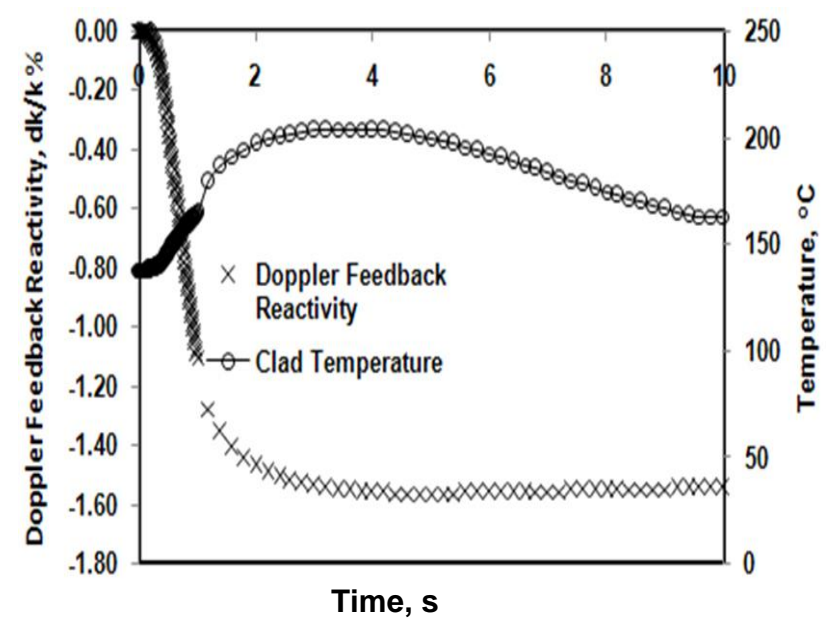

Fig. 5. Variation of cladding temperature with Doppler feed feedback reactivity for step $1.8 \% \mathrm{dk} / \mathrm{k}$.

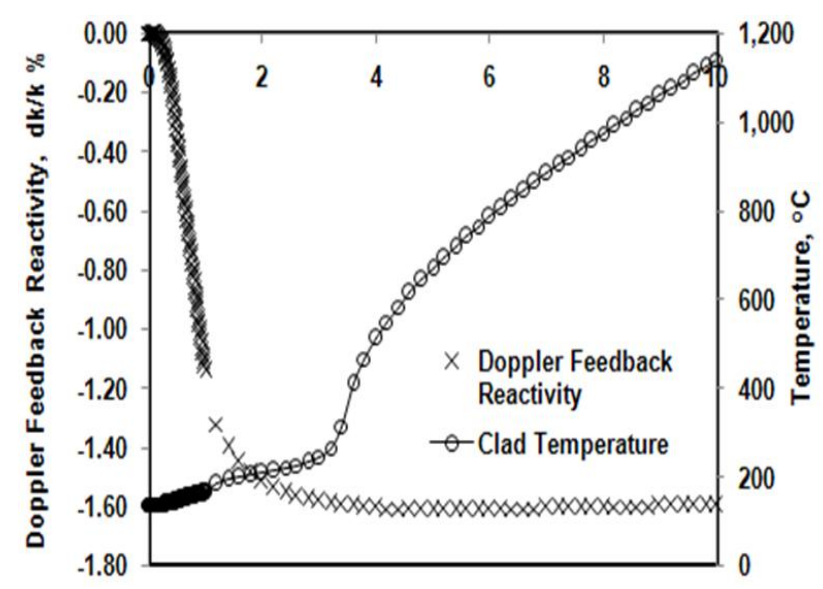

Fig. 6. Variation of cladding temperature with feedback reactivity for $1.85 \% \mathrm{dk} / \mathrm{k}$ step reactivity.

Figure 7 presents cladding temperature profiles for ramp insertion of reactivity. For $0.5 \%$ $\mathrm{dk} / \mathrm{k}$ and $1.5 \% \mathrm{dk} / \mathrm{k}$ reactivity insertions, the cladding temperature rose to as high as $144.84{ }^{\circ} \mathrm{C}$ at $10 \mathrm{~s}$ and $160{ }^{\circ} \mathrm{C}$ at $10.8 \mathrm{~s}$ before reaching stable values of $144.31{ }^{\circ} \mathrm{C}$ and $158.28{ }^{\circ} \mathrm{C}$, respectively. For both $1.9 \% \mathrm{dk} / \mathrm{k}$ and $1.95 \% \mathrm{dk} / \mathrm{k}$, the cladding temperature gradually increased until reaching $163{ }^{\circ} \mathrm{C}$ at $9.6 \mathrm{~s}$ at first instance. Afterward, for $1.9 \% \mathrm{dk} / \mathrm{k}$, the temperature reached its first peak at $174.92{ }^{\circ} \mathrm{C}$ at $12.8 \mathrm{~s}$, from which it drops to a stable value of $163.22{ }^{\circ} \mathrm{C}$ at $18.2 \mathrm{~s}$. For $1.95 \% \mathrm{dk} / \mathrm{k}$, it reached a peak value of $187.93{ }^{\circ} \mathrm{C}$ at $14.6 \mathrm{~s}$ and then gradually decreased and reached a stable value of
$163.12{ }^{\circ} \mathrm{C}$ at $47 \mathrm{~s}$. For $2.0 \% \mathrm{dk} / \mathrm{k}$, the temperature increased to $163.22{ }^{\circ} \mathrm{C}$ at $18.2 \mathrm{~s}$ from which another increase took the temperature to exceed the design limit. Hence, Doppler feedback reactivity was not strong enough at this edge of reactivity to bring the temperature to some steady state value. Comparison between Fig. 2 and Fig. 7 suggests that when the reactor is unprotected, the impact of feedback reactivity is visibly more profound in case of ramp insertion of reactivity which causes reactor to remain safe until $1.99 \% \mathrm{dk} / \mathrm{k}$ reactivity during scram disable. This, in turn, agrees with the fact that step reactivity insertion is more severe than ramp reactivity insertion.

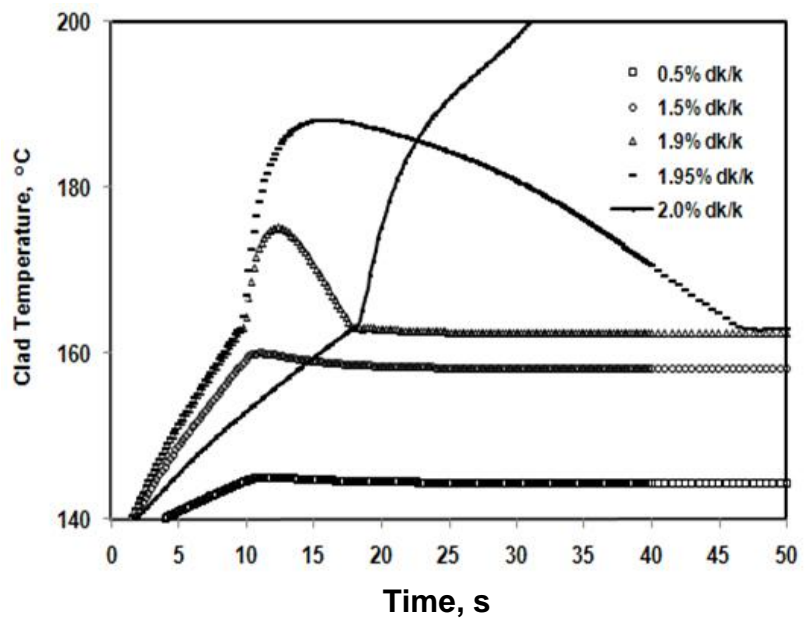

Fig. 7. Fuel cladding temperature behavior for different ramp reactivities.

\section{CONCLUSION}

An RIA analysis has been carried out through the modeling of unprotected reactor transients. Although the analysis already been published for protected TRIGA, but RIA analysis for unprotected TRIGA had not been conducted before and the present work could greatly contribute to the reactor operators to reuse data in any future need. The ranges of reactivity considered here are relatively wide; nevertheless, the reactor was found safe to up to $1.8 \% \mathrm{dk} / \mathrm{k}$ (\$2.57) for step reactivity and $1.99 \% \mathrm{dk} / \mathrm{k}$ (\$2.84) for ramp reactivity. Prompt negative temperature coefficient of reactivity, in addition to Doppler feedback reactivity, played an important role in bringing the cladding maximum temperature within the design limit. However, the insertion time of reactivity, $10 \mathrm{~s}$, seems too long. Therefore, all these factors in combination can be expected to keep the reactor in the safe side.

Also, cladding temperature appeared to exceed the design limit beyond certain magnitude of 
reactivity insertion. However, it happened so quickly that it caused negligible heat transfer from cladding to coolant; thus, no bubbling appeared in the reactor coolant. The effects of feedback reactivity during unprotected condition of reactor was also found to be more profound in ramp reactivity insertion than in step reactivity insertion, as would be expected. Within the limitations of this analysis, it could be concluded that the EUREKA code predicts the sequence of unprotected transient scenario of TRIGA reactor with good approximation and the model could be used for further studies.

\section{ACKNOWLEDGMENT}

The authors acknowledge Dr. Masanori Kaminaga of Japan Atomic Energy Agency (JAEA) for his generous support during the progress of the TRIGA core modeling.

\section{REFERENCE}

1. N.H. Badrun, M.H. Altaf, M.J.H. Khan et al., Ann. of Nucl. Energy 41 (2012) 40.

2. M.H. Altaf, N.H. Badrun and M.J.H. Khan, The Nucleus 51 (2014) 387.

3. N.H. Badrun, M.H. Altaf and M.T. Chowdhury, Ann. of Nucl. Energy 85 (2015) 394.

4. M. Kaminaga, EUREKA-2/RR Code, Japan Atomic Energy Agency (1996) 1.

5. Anonymous, Safety Analysis Report for the 3000 kW Forced Flow TRIGA Mark-II Reactor, E-117-990, General Atomic (1981) 6. 